\title{
A tribological model for chocolate in the mouth \\ General implications for slurry-lubricated hard/soft sliding counterfaces
}

\author{
Journal Article \\ Author(s): \\ Lee, Seunghwan; Heuberger, Manfred; Rousset, Philippe; Spencer, Nicholas D. \\ Publication date: \\ 2004-04 \\ Permanent link: \\ https://doi.org/10.3929/ethz-b-000052219 \\ Rights / license: \\ In Copyright - Non-Commercial Use Permitted \\ Originally published in: \\ Tribology Letters 16(3), https://doi.org/10.1023/B:TRIL.0000009735.06341.32
}




\title{
A tribological model for chocolate in the mouth: General implications for slurry-lubricated hard/soft sliding counterfaces
}

\author{
Seunghwan Lee ${ }^{\mathrm{a}}$, Manfred Heuberger ${ }^{\mathrm{a}}$, Philippe Rousset ${ }^{\mathrm{b}}$ and Nicholas D. Spencer ${ }^{\mathrm{a}, *}$ \\ ${ }^{a}$ Laboratory for Surface Science and Technology, Department of Materials, Swiss Federal Institute of Technology (ETH), \\ Zürich, CH-8092, Switzerland \\ ${ }^{b}$ Nestlé Research Center, Department of Food Science and Process Research, Vers-chez-les-Blanc, 1000 Lausanne 26, Switzerland
}

Received 20 April 2003; accepted 4 August 2003

\begin{abstract}
We have investigated the rheological and lubrication properties of molten chocolate samples. To this end, a series of chocolate samples having various textural/compositional features have been prepared. The rheological properties of the chocolate samples are discussed in terms of the Casson model. The lubrication properties of the molten chocolate samples have been characterized by means of pin-on-disk tribometry. For the tribo-pairs, zirconia $\left(\mathrm{ZrO}_{2}\right)$ and poly(tetrafluoroethylene) (PTFE) have been used in all permutations for both slider (pin) and track (disk), providing the four tribo-pair combinations; $\mathrm{ZrO}_{2} / \mathrm{ZrO}_{2}, \mathrm{PTFE} / \mathrm{ZrO}{ }_{2}, \mathrm{ZrO}{ }_{2} /$ PTFE, and PTFE/PTFE. The results showed that both the rheological and lubrication properties of the chocolate samples are strongly influenced by the textural and compositional characteristics. The lubrication properties are further influenced by the choice of the tribo-pair. The different lubrication properties of the chocolate samples at different tribo-pairs are discussed in terms of particle behavior in the surrounding region of the inlet of the sliding tribo-pairs.
\end{abstract}

KEY WORDS: chocolate, slurry lubrication, hard/soft surface pairing, particle suspensions, third body

\section{Introduction}

Chocolate is a unique food that exists as a solid at room temperature, yet melts and turns into a viscous fluid at the temperature of the human mouth [1]. This is due to the melting of the fat components of chocolate, which bind a variety of organic particles together [1]. The fats include cocoa butter and milk fat, and the particles include cocoa solids, sugar, and, in the case of milk chocolate, milk powder. Surfactants (e.g. lecithin) are also added to facilitate the homogenous dispersion of the hydrophilic solid components (e.g. sugar) with the hydrophobic fat components. Molten chocolate thus can be considered as slurry composed of a high concentration of various organic particles suspended in a continuous fat phase.

The rheological properties of chocolate are crucial in both the manufacturing and the consumption process in the human mouth, and thus have been extensively investigated [1-2]. As chocolate is a well-known example of a non-Newtonian fluid, a non-conventional approach, such as the Casson model [3-4], is required to describe its rheological properties. Recently, tribological characterization has also been employed to assess the properties of chocolate [5-6], since both hydrodynamic and boundary lubrication regime come into play and rheological measurements alone cannot com-

\footnotetext{
* To whom correspondence should be addressed. E-mail: nicholas. spencer@mat.ethz.ch
}

pletely describe the behavior of chocolate at a sliding interface.

Particle-containing lubrication systems are also of more general interest. The presence of particles in oil or grease has a significant impact on the performance of those fluids as lubricants. The particles can be wear debris generated during tribological process, soot from engines, or particles that have been added deliberately to improve lubrication. A variety of particles, including $\mathrm{MoS}_{2}$ [7-16], graphite [14-19], fullerene [14], diamond [20], ceramics $[15,21]$, and metals $[15,22]$, have been added to lubricants to improve their properties. The effects vary enormously: Some studies report that particles improve anti-wear and lubricating performance [7-14,20], whereas others report a negligible or deleterious effect [15-19,21-22]. Many theoretical studies have also predicted both trends [23-29]. Clearly, the effect of particle addition on the lubricating properties of a fluid is strongly influenced by several parameters, such as the specific tribo-pair involved, the slide/roll ratio, the size, shape and chemical properties of the particles, the viscosity of the fluid, velocity, and load [7-29].

In this work, we have prepared a series of chocolate samples possessing various textural and compositional characteristics, in order to investigate their influence on rheological and tribological properties. As sliding interfaces, we have selected zirconia $\left(\mathrm{ZrO}_{2}\right)$ and poly (tetrafluoroethylene) (PTFE), representing both hard and soft counterfaces. These two materials have been used in all possible permutations, providing four combinations (pin material/disk material); (i) $\mathrm{ZrO}_{2} / \mathrm{ZrO}_{2}$ 
(hard on hard), (ii) PTFE/ $\mathrm{ZrO}_{2}$ (soft on hard), (iii) $\mathrm{ZrO}_{2} /$ PTFE (hard on soft), and (iv) PTFE/PTFE (soft on soft).

The selection of tribo-pairs based upon hardness difference is motivated by an attempt to emulate the hard and soft components in the human mouth (teeth, tongue, and palate) and to better understand the tribological processes involved during chocolate consumption in the human mouth [6]. In addition, we note that the influence of the relative hardness of the tribopair and particles in the lubricant has been rarely investigated in the literature concerning slurry lubrication [7-29].

\section{Experimental}

\subsection{Model chocolate samples}

The components of the investigated chocolate samples are listed in table 1. The particle components include sugar $(45 \mathrm{wt} \%)$, skim milk powder $(18 \mathrm{wt} \%)$, and cocoa solids $(5.4 \mathrm{wt} \%)$. The fat components include cocoa butter, milk fat, and lecithin and the contents are varied as shown below. In addition, vanillin is added as a minor component $(0.025 \mathrm{wt} \%)$. Based upon the basic recipe in table 1 , nineteen samples were produced by systematically varying the following parameters [6];

(1) mean particle size; 21 and $52 \mu \mathrm{m}$

(2) soya lecithin; 0.1 and $0.4 \mathrm{wt} \%$

(3) conching types (conching is a process which blends the chocolate ingredients and leads to enhanced flavors [1]); low shear/very long time $(24 \mathrm{~h})$, high shear/long time $(6 \mathrm{~h})$, and high shear/short time $(2 \mathrm{~h})$ (4) milk fat; 3.5, 5.75, and $8.0 \mathrm{wt} \%$

The effect of replacing cocoa butter by milk fat and variation of the conching type was found to be insignificant for both the rheological and tribological properties. Thus, the chocolate samples are labeled based upon their particle size, F (Fine, $21 \mu \mathrm{m}$ ) or $\mathbf{C}$ (Coarse, $52 \mu \mathrm{m})$, and lecithin content, $1(0.1 \%)$ or $4(0.4$ $\%$ ), only. The nineteen samples can be divided into four groups; F1, C1, F4, and C4. For each group, there are four or five samples with different values of milk fat content and conching type. A complete list of the chocolate samples with the varied parameters is presented in table 2 .

\subsection{Measurements of the rheological properties}

The rheological characteristics of the chocolate samples were measured at $40^{\circ} \mathrm{C}$ according to the International Office of Cocoa and Chocolate (IOCC) standard [1-2]. A Contraves (Zürich, Switzerland) Rheomat 115 apparatus with a DIN 125 cell was used. A Casson model was used to describe the viscosity [3-4]. The section of the experimental curves with positive slopes between 5 and $50 \mathrm{~s}^{-1}$ was fitted with the Casson equation to estimate the plastic viscosity, $\eta_{\mathrm{ca}}$, and the yield value, $\tau_{\mathrm{ca}}$.

\subsection{Measurements of the lubrication properties}

The lubrication properties of the chocolate samples between various tribo-pairs were characterized by means of a pin-on-disk tribometer (CSM, Neuchâtel, Switzerland). The entire set-up of the tribometer was housed in a plastic (PMMA) enclosure, which enabled the temperature and humidity of the experimental environment to be controlled. Before the start of the friction measurements, the chocolate samples were heated $\left(40 \pm 0.5^{\circ} \mathrm{C}\right)$ inside the tribometer enclosure. The tribometer enclosure was kept at this temperature throughout the measurement. The molten chocolate samples were then transferred onto the disk prior to the formation of the contact between the weighted pin and disk. The friction forces were measured under a fixed applied load $(10 \mathrm{~N})$. The analog output voltage of the tribometer, corresponding to the friction force, was recorded with a Macintosh Power PC using LabView and an ADC card of the MIO family (both from National Instruments, Austin, TX, USA). The raw data consisted of friction force as a function of time. In cases where the dependence of the friction forces on the velocity was investigated, the velocity was varied from $\sim 0.05 \mathrm{~mm} / \mathrm{s}$ to a maximum of $\sim 20 \mathrm{~mm} / \mathrm{s}$ by changing the rotational rate at a fixed radius $(6 \mathrm{~mm})$.

\subsection{Materials for the tribo-pairs}

The materials used for the tribo-pairs in this work were $\mathrm{ZrO}_{2}$ (Saphirwerk Industrieprodukte AG, Brügg, Switzerland) and PTFE (Maagtechnic, Dübendorf, Switzerland). These materials were used for both pin and disk, providing the combination of four tribo-pairs; (i) $\mathrm{ZrO}_{2} / \mathrm{ZrO}_{2}$ (ii) $\mathrm{PTFE} / \mathrm{ZrO}_{2}$ (iii) $\mathrm{ZrO}_{2} / \mathrm{PTFE}$, and

Table 1

The relative amounts (wt \%) of common components in the chocolate samples.

\begin{tabular}{|c|c|c|c|c|c|c|}
\hline \multicolumn{3}{|c|}{ Particle components } & \multicolumn{3}{|c|}{ Fat components } & \multirow{2}{*}{$\begin{array}{l}\text { Vanillin } \\
0.025 \%\end{array}$} \\
\hline $\begin{array}{l}\text { Sugar } \\
45 \%\end{array}$ & $\begin{array}{l}\text { Skim milk powder } \\
18 \%\end{array}$ & $\begin{array}{l}\text { Cocoa solids } \\
5.4 \%\end{array}$ & $\begin{array}{l}\text { Lecithin } \\
x \%(=0.1 \text { or } 0.4)\end{array}$ & $\begin{array}{l}\text { Milk fat } \\
y \%(=3.5,5.75, \text { or } 8 \%)\end{array}$ & $\begin{array}{l}\text { Cocoa butter } \\
31.7-x-y \%\end{array}$ & \\
\hline
\end{tabular}


Table 2

The list of the varied parameters of the chocolate samples; conching type, milk fat content, mean particle size, and lecithin content.

\begin{tabular}{|c|c|c|c|c|c|}
\hline $\begin{array}{l}\text { Sample } \\
\text { number }\end{array}$ & $\begin{array}{c}\text { Sample } \\
\text { group } \\
\text { notation }\end{array}$ & $\begin{array}{c}\text { * Mean } \\
\text { particle } \\
\text { size }\end{array}$ & $\begin{array}{c}\text { Lecithin } \\
\text { content }(\%)\end{array}$ & Conching type & $\begin{array}{c}\text { Milk fat } \\
\text { content }(\%)\end{array}$ \\
\hline 1 & $\mathrm{~F} 1$ & fine & 0.1 & low shear $/ 24 \mathrm{~h}$ & 3.5 \\
\hline 2 & F1 & fine & 0.1 & low shear $/ 24 \mathrm{~h}$ & 5.75 \\
\hline 3 & $\mathrm{~F} 1$ & fine & 0.1 & high shear $/ 6 \mathrm{~h}$ & 5.75 \\
\hline 4 & $\mathrm{~F} 1$ & fine & 0.1 & high shear $/ 6 \mathrm{~h}$ & 5.75 \\
\hline 5 & $\mathrm{C} 1$ & coarse & 0.1 & high shear $/ 6 \mathrm{~h}$ & 3.5 \\
\hline 6 & $\mathrm{C} 1$ & coarse & 0.1 & low shear $/ 24 \mathrm{~h}$ & 5.75 \\
\hline 7 & $\mathrm{C} 1$ & coarse & 0.1 & high shear $/ 2 \mathrm{~h}$ & 5.75 \\
\hline 8 & $\mathrm{C} 1$ & coarse & 0.1 & high shear $/ 2 \mathrm{~h}$ & 8.0 \\
\hline 9 & $\mathrm{C} 1$ & coarse & 0.1 & high shear $/ 6 \mathrm{~h}$ & 8.0 \\
\hline 10 & F4 & fine & 0.4 & high shear $/ 2 \mathrm{~h}$ & 3.5 \\
\hline 11 & F4 & fine & 0.4 & high shear $/ 6 \mathrm{~h}$ & 3.5 \\
\hline 12 & F4 & fine & 0.4 & low shear $/ 24 \mathrm{~h}$ & 3.5 \\
\hline 13 & F4 & fine & 0.4 & low shear $/ 24 \mathrm{~h}$ & 5.75 \\
\hline 14 & F4 & fine & 0.4 & high shear $/ 2 \mathrm{~h}$ & 8.0 \\
\hline 15 & $\mathrm{C} 4$ & coarse & 0.4 & high shear $/ 2 \mathrm{~h}$ & 3.5 \\
\hline 16 & $\mathrm{C} 4$ & coarse & 0.4 & low shear $/ 24 h$ & 3.5 \\
\hline 17 & $\mathrm{C} 4$ & coarse & 0.4 & high shear $/ 2 \mathrm{~h}$ & 5.75 \\
\hline 18 & $\mathrm{C} 4$ & coarse & 0.4 & high shear $/ 6 \mathrm{~h}$ & 5.75 \\
\hline 19 & $\mathrm{C} 4$ & coarse & 0.4 & low shear $/ 24 \mathrm{~h}$ & 8.0 \\
\hline
\end{tabular}

* "fine" represents mean particle size of $21 \mu \mathrm{m}$ and "coarse" represents mean particle size of $52 \mu \mathrm{m}$.

(iv) PTFE/PTFE. The radii of the spherical pins and disks were 3 and $30 \mathrm{~mm}$, respectively. The $\mathrm{ZrO}_{2}$ pin, $\mathrm{ZrO}_{2}$ disk and PTFE pin were highly polished by the manufacturers and used as received without further treatment. The PTFE disks were polished prior to each measurement using sand paper (grade $\mathrm{P} 500>$ grade P1200 > grade PO).

\section{Results}

\subsection{Rheological properties of the chocolate samples}

As previously mentioned, the rheological properties of the model chocolate samples were characterized employing the Casson model $[24,25]$

$$
\sqrt{\tau}=\sqrt{\tau_{\mathrm{ca}}}+\sqrt{\eta_{\mathrm{ca}}} \cdot \sqrt{D}
$$

where $\tau$ is the shear stress, $\tau_{\mathrm{ca}}$ is the Casson yield value, $D$ is the shear rate, and $\eta_{\mathrm{ca}}$ is the Casson plastic viscosity. The yield value represents the shear stress required to break the structure of the chocolate and to initiate shear motion of the chocolate samples. The plastic viscosity represents the force necessary to maintain shear of the chocolates at high velocities [1,2]. In figure 1 , the average values of $\tau_{\mathrm{ca}}$ and $\eta_{\mathrm{ca}}$ for each chocolate sample group are plotted. The relative magnitudes of yield value and plastic viscosity are in the order of F1 $>$ F4 $\geq \mathrm{C} 1 \geq \mathrm{C} 4$ and F1 $>\mathrm{C1} \geq \mathrm{F4} \geq \mathrm{C4}$ respectively. F1 is clearly distinguished from the other groups, while the distinction among the other groups is not as clear. This observation implies that either increasing lecithin content from 0.1 to $0.4 \%$ or increasing mean particle size from 21 to $52 \mu \mathrm{m}$, thus effectively decreasing particle surface area, results in a significant reduction of both yield value and plastic viscosity. The Casson yield value and Casson plastic viscosity of the individual chocolate samples are listed in table 3 .

\subsection{Lubricating properties of the chocolate samples at the $\mathrm{ZrO}_{2} / \mathrm{ZrO}_{2}$ interface (hard on hard)}

The frictional properties of the chocolate-lubricated $\mathrm{ZrO}_{2} / \mathrm{ZrO}_{2}$ tribo-pair were characterized by determining coefficients of friction $(\mu=\mathrm{d} F / d N, N=10 \mathrm{~N})$ as a function of velocity within the range from $\sim 0.05$ to $\sim 2.0 \mathrm{~mm} / \mathrm{s}$. The sliding of the $\mathrm{ZrO}_{2} / \mathrm{ZrO}_{2}$ tribo-pair at higher velocities than $\sim 2.0 \mathrm{~mm} / \mathrm{s}$, whether dry or lubricated by the chocolate samples, was observed to exhibit a significant and irregular increase of the friction forces within the time scale of the measurement. The coefficients of friction of dry and fat-lubricated sliding have also been obtained for comparison. The results are plotted in figure 2. In this plot, the chocolate samples belonging to a certain group, F1, C1, F4 or C4, are designated by the same corresponding symbols. For clarity, error bars (typically $\sim \pm 0.005$ for $\mu$ ) are not shown for all the plots below.

As shown in figure 2, the coefficients of friction, $\mu$, for dry sliding were found to increase slightly with 


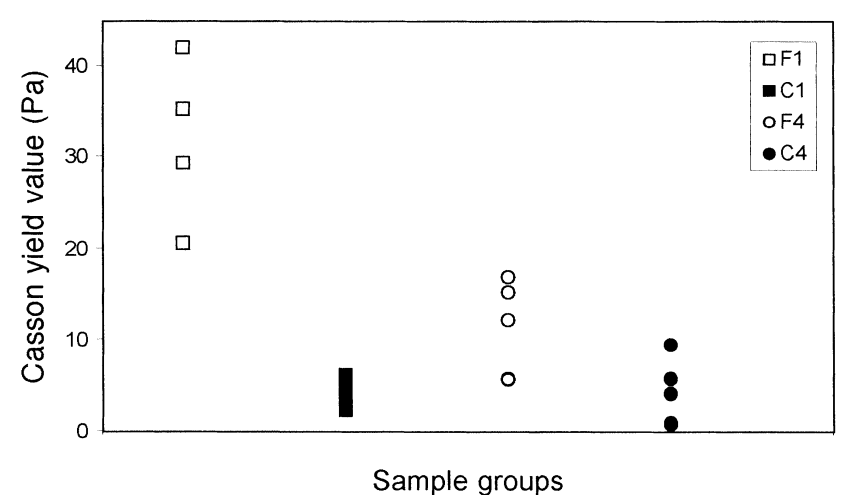

(a)

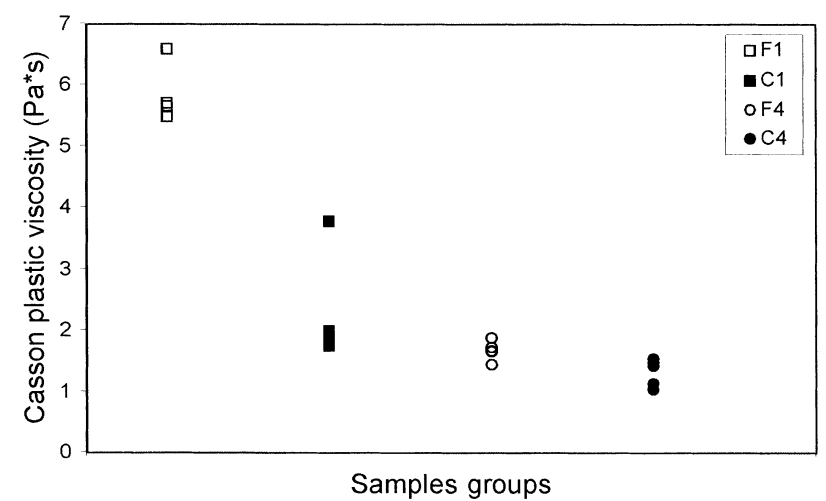

(b)

Figure 1. (a) The average Casson yield value, $\tau_{\mathrm{ca}}$, and (b) the average Casson plastic viscosity, $\eta_{\text {ca }}$, for the chocolate sample groups $\left(T=40^{\circ} \mathrm{C}\right)$.

Table 3

Rheological properties of the chocolate samples.

\begin{tabular}{lccc}
\hline $\begin{array}{l}\text { Sample } \\
\text { number }\end{array}$ & $\begin{array}{c}\text { Sample } \\
\text { group } \\
\text { notation }\end{array}$ & $\begin{array}{c}\text { Casson } \\
\text { plastic } \\
\text { viscosity } \\
\text { (Pas) }\end{array}$ & $\begin{array}{c}\text { Casson } \\
\text { yield } \\
\text { value } \\
\text { (Pa) }\end{array}$ \\
\hline 1 & F1 & 6.59 & 29.36 \\
2 & F1 & 5.7 & 20.62 \\
3 & F1 & 5.66 & 35.32 \\
4 & F1 & 5.48 & 42.08 \\
5 & C1 & 1.75 & 3.86 \\
6 & C1 & 3.79 & 6.11 \\
7 & C1 & 1.98 & 4.85 \\
8 & C1 & 1.92 & 5.15 \\
9 & C1 & 1.77 & 2.3 \\
10 & F4 & 1.73 & 16.86 \\
11 & F4 & 1.44 & 12.2 \\
12 & F4 & 1.66 & 5.68 \\
13 & F4 & 1.88 & 5.71 \\
14 & F4 & 1.64 & 15.2 \\
15 & C4 & 1.12 & 9.41 \\
16 & C4 & 1.54 & 0.87 \\
17 & C4 & 1.42 & 4.09 \\
18 & C4 & 1.03 & 5.73 \\
19 & C4 & 1.48 & 0.71 \\
\hline
\end{tabular}

increasing velocity (from 0.187 to 0.234 ). Lubrication by the fat components alone exhibited reduced and virtually constant $\mu$ values within the same range of the velocity; $0.100 \pm 0.001$ by milk fat and $0.084 \pm 0.003$ by cocoa butter. The $\mathrm{ZrO}_{2} / \mathrm{ZrO}_{2}$ tribo-pair exhibited further reduction of $\mu$ when it was lubricated by the molten chocolate samples. The $\mu$ was found to exhibit different velocity dependence for the chocolate samples having different textural/compositional features. For F1 and $\mathbf{C 1}, \mu$ decreased with increasing velocity (from 0.074 to 0.059 on average for $\mathbf{F} 1$ and from 0.061 to 0.051 on average for $\mathbf{C 1}$ ), while for $\mathbf{F 4}$ and $\mathbf{C 4}, \mu$ increased with increasing velocity (from 0.042 to 0.048 on average for F4 and from 0.037 to 0.050 on average for C4). The differences between different sample groups are higher at low velocities. The order of $\mu$ is $\mathbf{F 1} \geq \mathbf{C 1} \geq \mathbf{F 4} \geq \mathbf{C 4}$. The differences disappear at high velocities. It is noted that neither velocity dependence nor lubricant texture/ composition dependence are particularly pronounced in the chocolate-lubricated sliding of $\mathrm{ZrO}_{2} / \mathrm{ZrO}_{2}$.

Among the four tribo-pairs employed in this work, $\mathrm{ZrO}_{2} / \mathrm{ZrO}_{2}$ was observed to be the only tribo-pair for which the chocolate samples show lower friction forces than the pure fat components. Furthermore, comparing the same chocolate sample as a lubricant over all pairs, $\mathrm{ZrO}_{2} / \mathrm{ZrO}_{2}$ showed the lowest coefficient of friction. In other words, the presence of the particles in the chocolate samples appears to contribute to lower friction in the lubrication of $\mathrm{ZrO}_{2} / \mathrm{ZrO}_{2}$ interface.

\subsection{Lubrication properties of the chocolate samples at the PTFE $/ \mathrm{ZrO}_{2}$ interface (soft on hard)}

As the chocolate-lubricated sliding of PTFE $/ \mathrm{ZrO}_{2}$ pair exhibited stable and reproducible frictional behavior, even at velocities higher than $\sim 2.0 \mathrm{~mm} / \mathrm{s}$, the range was extended from $\sim 0.05$ to $\sim 20 \mathrm{~mm} / \mathrm{s}$, as shown in figure 3 .

The dry sliding showed a gradual increase of the coefficient of friction with increasing velocity (from 0.012 to 0.049 ). The lubrication by the fat components led to fairly constant friction over the same velocity range; $\mu=0.015 \pm 0.003$ by milk fat and $0.019 \pm 0.002$ by cocoa butter. Thus, the fat components appeared to reduce the friction slightly at high velocities. Chocolate lubrication, however, exhibited significantly higher $\mu$ values within the measured velocity range. The magnitude of the increase was shown to be strongly dependent on the velocity and textural/compositional features. The $\mu$ decreased with increasing velocity for F1, C1, and F4 (from 0.151 to 0.082 on average for $\mathbf{F 1}$, from 0.131 to 0.072 on average for $\mathbf{C 1}$, and from 0.092 to 0.077 for F4), while it increased with increasing velocity for $\mathbf{C 4}$ (from 0.052 to 0.076 on average). The $\mu$ values for different chocolate sample groups are quite distinct at low velocities and were in the order of 


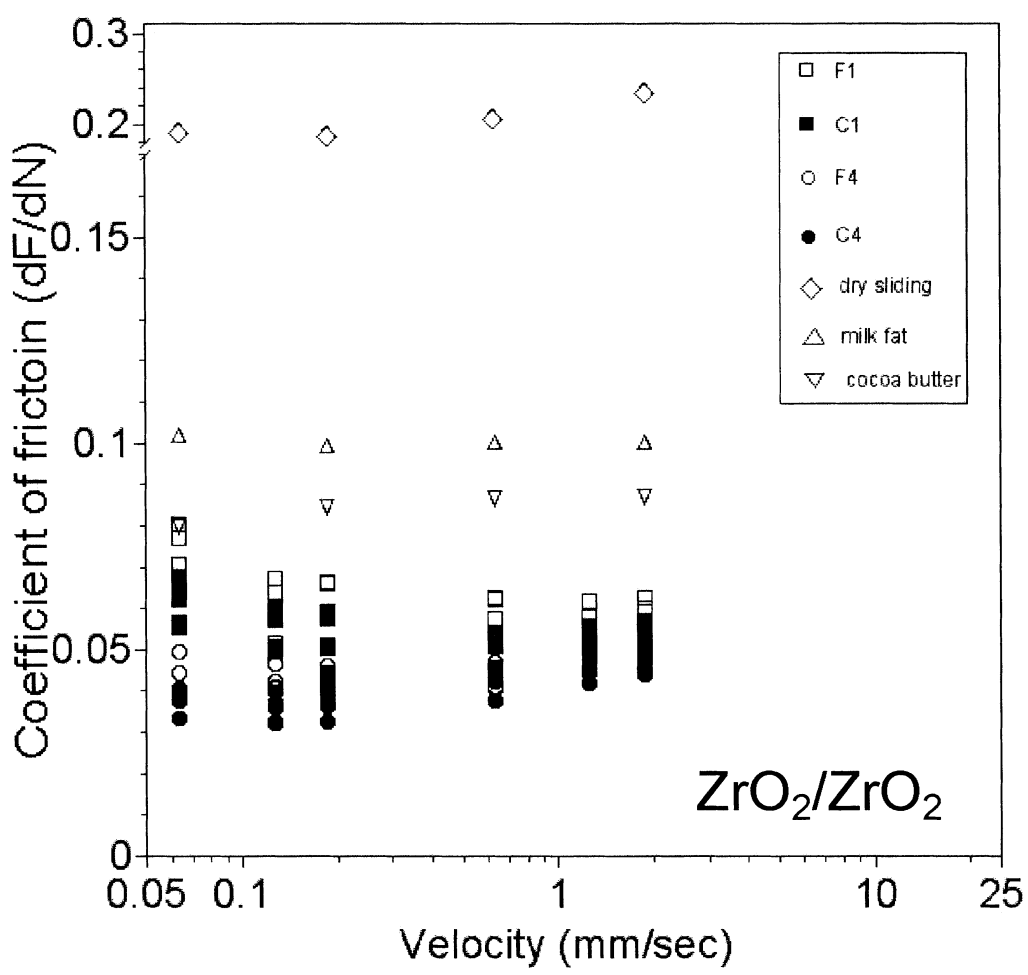

Figure 2. The coefficients of friction versus velocity plots of dry, the fat, and the chocolate-lubricated sliding of $\mathrm{ZrO}_{2} / \mathrm{ZrO}_{2}$ tribo-pair $\left(T=40^{\circ} \mathrm{C}\right.$, load $\left.=10 \mathrm{~N}\right)$.

$\mathbf{F 1}>\mathbf{C 1}>\mathbf{F 4}>\mathbf{C 4}$. As in the case of $\mathrm{ZrO}_{2} / \mathrm{ZrO}_{2}$, this difference disappeared at higher velocities. Surface analysis of the $\mathrm{ZrO}_{2}$ disk following the fat- or chocolate-lubricated sliding using X-ray photoelectron spectroscopy (XPS) showed no evidence for PTFE transfer.

The lubricating effect of the chocolate sample groups and the resulting velocity-dependent frictional behavior was similar for both $\mathrm{ZrO}_{2} / \mathrm{ZrO}_{2}$ and PTFE $/ \mathrm{ZrO}_{2}$ tribopairs; (i) the coefficients of friction are in the same order of F1, C1, F4 and C4 (ii) the difference in the coefficient of friction is more pronounced at low velocities (iii) the velocity-dependent frictional behavior shifts from a decreasing to an increasing trend in the order F1, C1, F4, C4. Nevertheless, replacement of the one hard counterface $\left(\mathrm{ZrO}_{2}\right)$ by a soft counterface (PTFE) led to several differences; (i) the $\mathrm{ZrO}_{2} / \mathrm{ZrO}_{2}$ pair exhibited lower $\mu$ values when lubricated by the chocolate samples than by the fats, while the PTFE $/ \mathrm{ZrO}_{2}$ pair exhibited higher $\mu$ values when lubricated by the chocolate samples than the fats (ii) PTFE $/ \mathrm{ZrO}_{2}$ always displayed higher $\mu$ values than $\mathrm{ZrO}_{2} / \mathrm{ZrO}_{2}$ for the same chocolate sample (see figures 2 and 3); the difference is systematically correlated with the textural/compositional parameters of the chocolate samples and is highest when F1 is employed as a lubricant, followed by $\mathbf{C 1}$ and $\mathbf{F 4}$, and C4 (iii) $\mathrm{PTFE} / \mathrm{ZrO}_{2}$ exhibited a more pronounced velocity dependence than $\mathrm{ZrO}_{2} / \mathrm{ZrO}_{2}$. Furthermore, the distinction between the groups of chocolate samples at low velocities is clearer when the chocolate samples lubricate the PTFE $/ \mathrm{ZrO}_{2}$ tribo-pair than $\mathrm{ZrO}_{2} / \mathrm{ZrO}_{2}$.

\subsection{Lubrication properties of the chocolate samples at the $\mathrm{ZrO}_{2}$ /PTFE interface (hard on soft)}

The $\mathrm{ZrO}_{2} / \mathrm{PTFE}$ interface is an inversion of the PTFE $/ \mathrm{ZrO}_{2}$ interface, for which one might expect similar tribological properties. However, with pin-on-disk geometry, the chocolate-lubricated $\mathrm{ZrO}_{2} /$ PTFE has been observed to exhibit significantly different behavior from that of PTFE $/ \mathrm{ZrO}_{2}$. Figure 4 shows the recorded friction versus time data of PTFE $/ \mathrm{ZrO}_{2}$ and $\mathrm{ZrO}_{2} /$ PTFE lubricated by $\mathbf{C 4}$ (sample number 17 in table 1 , velocity at $0.188 \mathrm{~mm} / \mathrm{s}$ ). In this plot, the $x$-axis represents the time scale and thus shows the repeated contact position along the track (5 rotations). When the measurement was performed in the absence of the chocolate samples, whether dry or fatlubricated, $\mathrm{ZrO}_{2} / \mathrm{PTFE}$ exhibited slightly higher friction forces, yet no other specific difference was observed. When the tribo-pairs were lubricated by the chocolate samples, a series of spikes in the friction signal was observed for $\mathrm{ZrO}_{2} /$ PTFE, but not for PTFE $/ \mathrm{ZrO}_{2}$ (figure 4). Controlled measurements of $\mathrm{ZrO}_{2} / \mathrm{PTFE}$ from various starting positions revealed that the positions of the spikes corresponds to the initial loading 


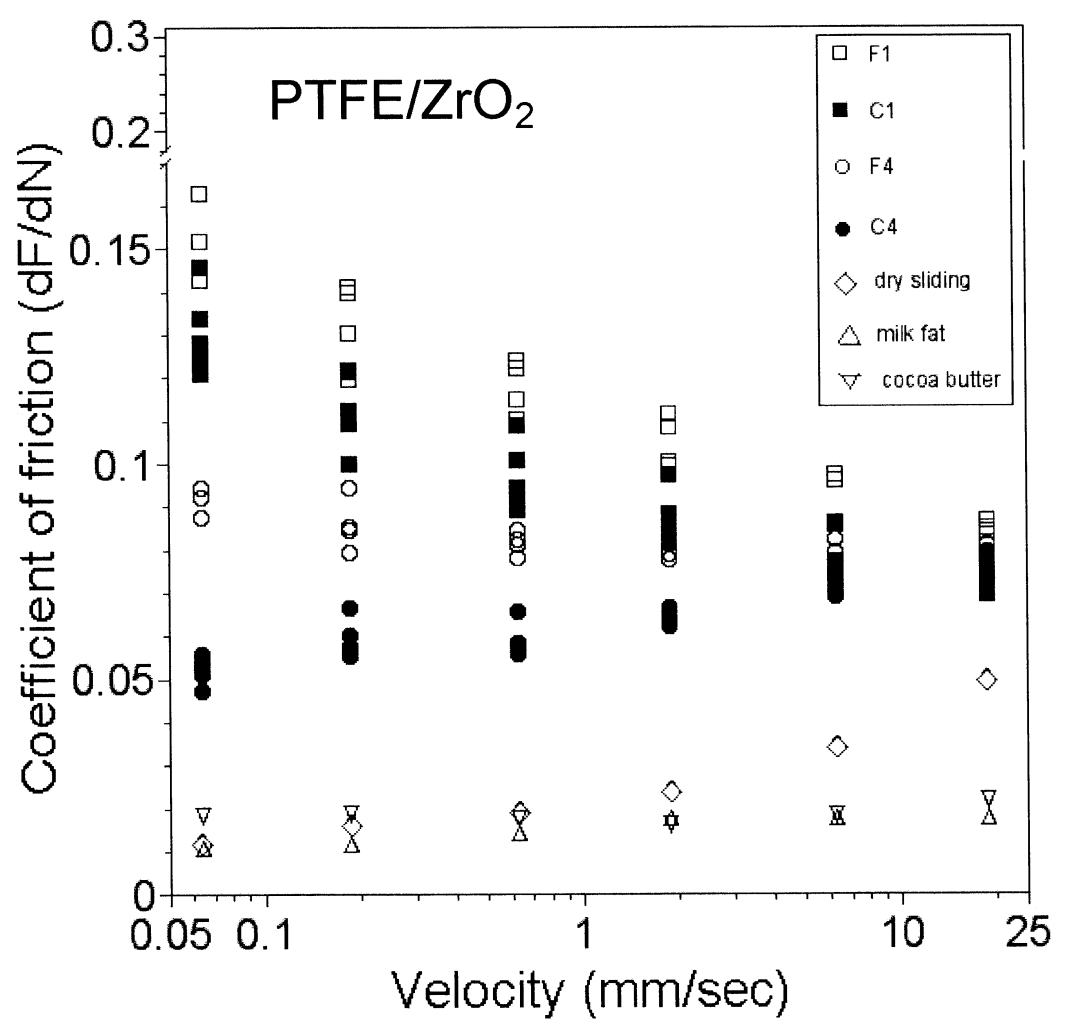

Figure 3. The coefficients of friction versus velocity plots of dry, the fat, and the chocolate-lubricated sliding of PTFE/ZrO ${ }_{2}$ tribo-pair $\left(T=40^{\circ} \mathrm{C}, \operatorname{load}=10 \mathrm{~N}\right)$.

point of the weighted pin-on-disk, and the frequency of the spikes corresponds to the rotational frequency of the disk.

The occurrence of these spikes is influenced by the textural/compositional parameters of the chocolate samples. In figure 5, representative raw data of friction forces-versus-time plots for each group of samples measured under a fixed velocity $(0.188 \mathrm{~mm} / \mathrm{s})$ are presented. In the case of $\mathbf{C 4}$ (sample number 14 in table 2), the spiky friction force signal is observed at the loading points only (figure 5(d)). Repeated measurements up to a maximum of 500 rotations showed that this behavior persists within these cycles. In the case of F1 (sample number 1 in table 2), the friction spikes rapidly develop even in regions outside the initial loading point (figure 5(a)). The other cases, $\mathbf{C 1}$ (sample number 5 in table 2) and $\mathbf{F 4}$ (sample number 10 in table 2), show a behavior between these two extremes (figure $5(\mathrm{~b})$ and (c)).

The coefficients of friction for chocolate-lubricated sliding as well as dry and fat-lubricated sliding of $\mathrm{ZrO}_{2} /$ PTFE were obtained by averaging the friction signals, including spikes, over 10 rotations under a fixed velocity $(0.188 \mathrm{~mm} / \mathrm{s})$. The results are presented in figure 6 . The $\mu$ of dry and fat-lubricated sliding of $\mathrm{ZrO}_{2} / \mathrm{PTFE}$ has been measured to be 0.070 (dry), 0.060 (milk fat), and 0.058 (cocoa butter) respectively. As in the case of PTFE $/ \mathrm{ZrO}_{2}$, the $\mu$ of chocolate-lubricated $\mathrm{ZrO}_{2} /$

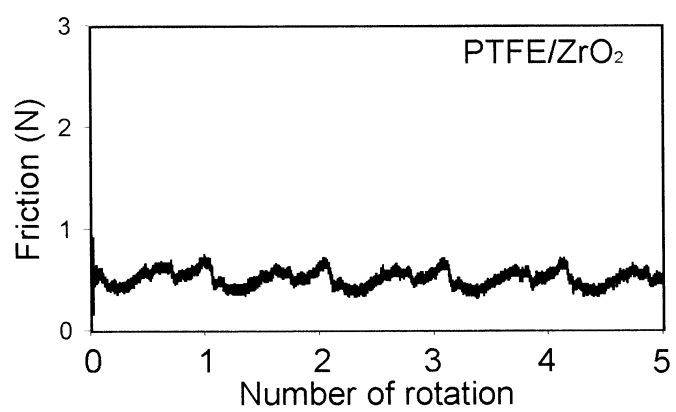

(a)

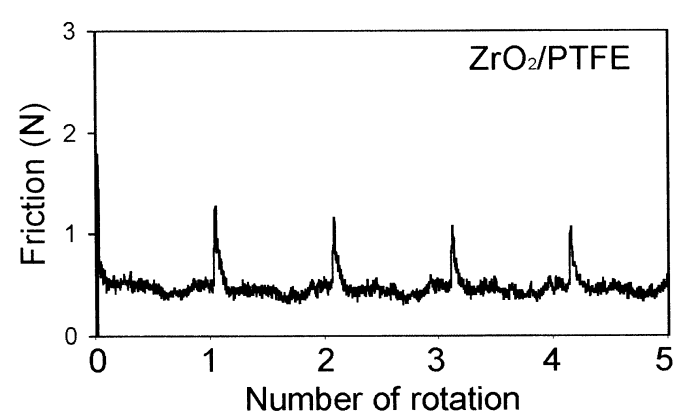

(b)

Figure 4. The friction forces of the chocolate-lubricated (C4, sample number 17 in table 2) sliding of (a) PTFE/ $\mathrm{ZrO}_{2}$ and (b) $\mathrm{ZrO}_{2} / \mathrm{PTFE}$ tribo-pairs as a function of time (or the number of rotation) $\left(T=40^{\circ} \mathrm{C}\right.$, load $=10 \mathrm{~N}$, velocity $\left.=0.188 \mathrm{~mm} / \mathrm{s}\right)$. 


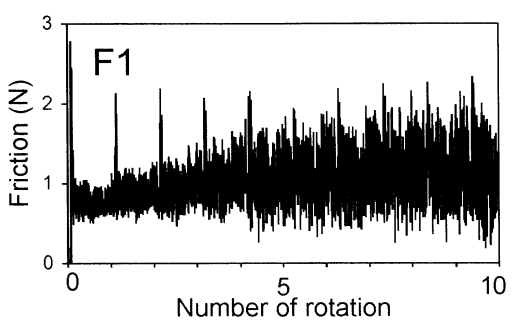

(a)

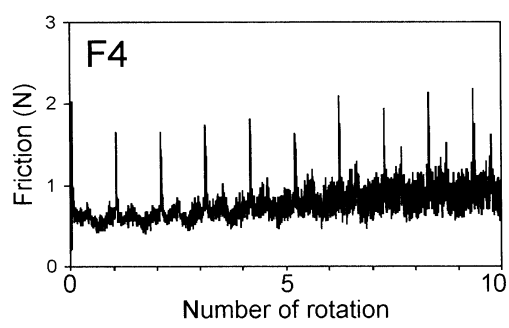

(c)

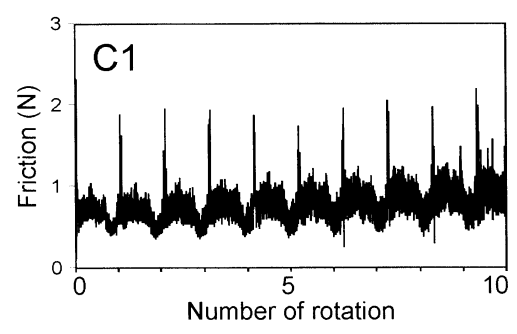

(b)

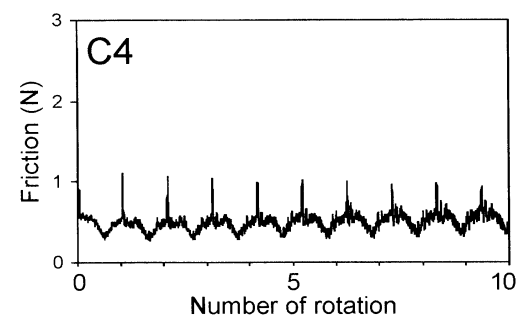

(d)

Figure 5. The friction forces of $\mathrm{ZrO}_{2}$ /PTFE tribo-pair lubricated by four different chocolate samples as a function of time (or the number of rotation) (a) F1 (sample number 1 in table 2) (b) C1 (sample number 5 in table 2) (c) F4 (sample number 10 in table 2) and (d) C4 (sample number 14 in table 2) $\left(T=40^{\circ} \mathrm{C}\right.$, load $=10 \mathrm{~N}$, velocity $\left.=0.188 \mathrm{~mm} / \mathrm{s}\right)$.

PTFE was measured to be in the order of F1 $(0.132$ $\pm 0.023)>\mathbf{C 1}(0.109 \pm 0.031)>\mathbf{F 4}(0.067 \pm 0.008)>\mathbf{C 4}$ $(0.051 \pm 0.003)$.

\subsection{Lubrication properties of the chocolate samples at PTFE/PTFE (soft on soft)}

Finally, the frictional properties of chocolate-lubricated PTFE/PTFE have been characterized by acquiring coefficients of friction as a function of velocity. As in the

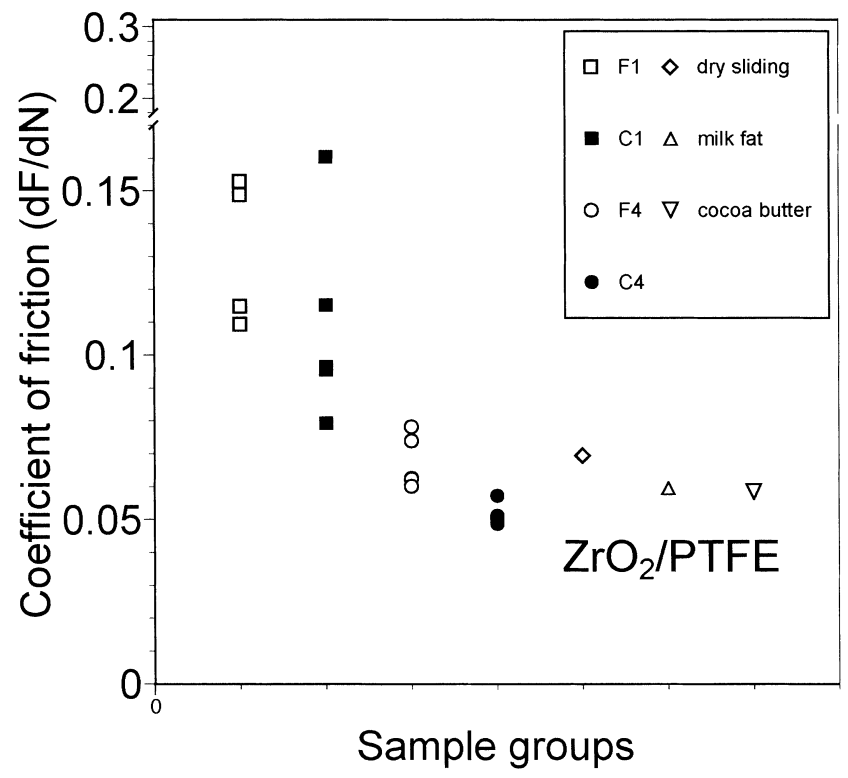

Figure 6. The coefficients of friction of dry, the fat, and the chocolatelubricated sliding of $\mathrm{ZrO}_{2} /$ PTFE tribo-pair $\left(T=40^{\circ} \mathrm{C}\right.$, load $=$ $10 \mathrm{~N}$, velocity $=0.188 \mathrm{~mm} / \mathrm{s}$ ). case of $\mathrm{ZrO}_{2} / \mathrm{ZrO}_{2}$, the chocolate-lubricated sliding of PTFE/PTFE also exhibited a rapid increase of friction forces at high velocities $(>\sim 2 \mathrm{~mm} / \mathrm{s})$, thus the range was selected from $\sim 0.05$ to $2.0 \mathrm{~mm} / \mathrm{s}$. The data are shown in figure 7.

The $\mu$ of dry PTFE/PTFE was found to increase slightly with increasing velocity; from 0.036 to 0.049 . In contrast to the dry case, the $\mu$ of fat-lubricated PTFE/ PTFE was found to decrease slightly with increasing velocity; from 0.040 to 0.034 by milk fat and from 0.036 to 0.030 by cocoa butter). Thus, the fat components appeared to reduce the friction of PTFE/PTFE mainly at high velocities. As in the case of PTFE/ $\mathrm{ZrO}_{2}$ and $\mathrm{ZrO}_{2} / \mathrm{PTFE}$, the lubrication of PTFE/PTFE with chocolate samples resulted in a significant increase of the coefficients of friction compared with dry sliding or fat lubrication. For all chocolate sample groups, the $\mu$ values were virtually constant as a function of velocity and in the order of $\mathbf{C 1}$ $(0.126 \pm 0.007) \approx \mathbf{C 4}(0.119 \pm 0.009) \geq \mathbf{F 1}(0.106 \pm 0.007)$ $\approx \mathbf{F} 4(0.102 \pm 0.005)$. In contrast to previous cases, where the friction is roughly in the decreasing order $\mathbf{F 1}, \mathbf{C 1}, \mathbf{F} 4$ and $\mathbf{C 4}$, the chocolate-lubricated PTFE/PTFE is dominated by the effects of particle size in the chocolate samples. It is also noted that the chocolate-lubricated PTFE/PTFE exhibited none of the spiky frictional features that were observed with $\mathrm{ZrO}_{2}$ /PTFE although the same soft track material was employed.

\section{Discussion}

\subsection{General consideration}

As mentioned in the Introduction, the choice of the materials for the tribo-pair in this work was motivated 


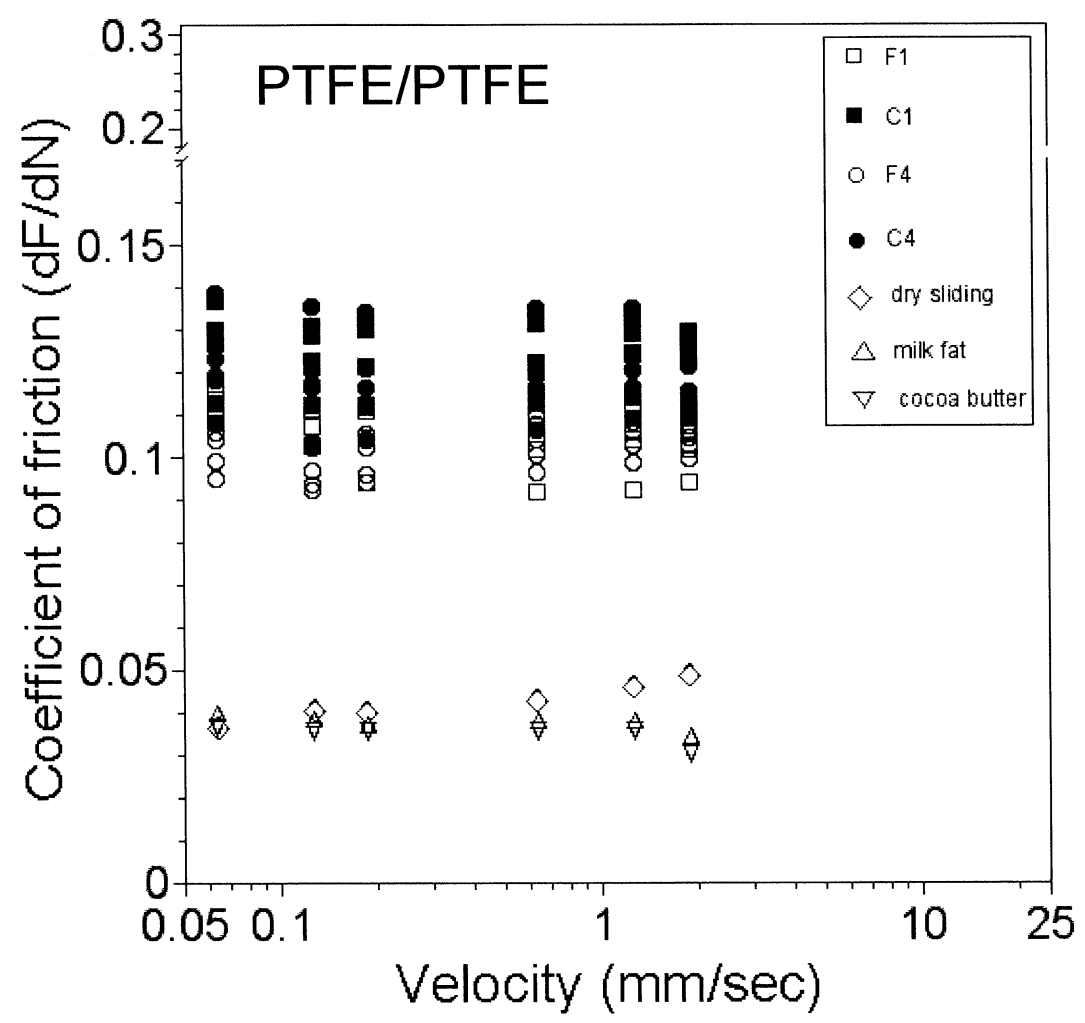

Figure 7. The coefficients of friction versus velocity plots of dry, the fat, and the chocolate-lubricated sliding of PTFE/PTFE tribo-pair $\left(T=40^{\circ} \mathrm{C}, \operatorname{load}=10 \mathrm{~N}\right)$.

by the hardness difference; $\mathrm{ZrO}_{2}$ represents a hard material (Vickers Hardness $1200 \mathrm{Hv}$ [30]) while PTFE represents a soft material (Vickers hardness $32 \mathrm{Hv}$ [31]). The un-lubricated sliding of these materials at various combinations revealed that they possess significantly different frictional properties. As shown in figure 2, the $\mathrm{ZrO}_{2} / \mathrm{ZrO}_{2}$ exhibits high $\mu$ values, $\sim 0.2$, while the cases involving PTFE showed significantly lower $\mu$ values, $\sim 0.05$ or less. The lower friction of the tribo-pair involving PTFE is attributed to better lubricating properties of PTFE itself [32,33]. For this reason, negligible significant friction reduction is observed for tribo-pairs involving PTFE, while a considerable friction reduction is observed for $\mathrm{ZrO}_{2} / \mathrm{ZrO}_{2}$ when it is lubricated by the fat components.

The primary difference of the model chocolate samples compared with the fat components as lubricants is that the chocolate samples contain a high concentration of particles suspended in a continuous fat phase $(\sim 70 \mathrm{wt} \%$ in this work). The presence of the particles in the fat phase causes two major changes in lubricant properties; (1) the viscosity of the fluid generally increases and (2) the tribopairs are subjected to abrasive wear. Typical kinematic viscosity of the vegetable oils is less than $50 \mathrm{cSt}$ $\left(1 \mathrm{cSt}=10^{-6} \mathrm{~m}^{2} \mathrm{~s}^{-1}\right.$ and the density is around $1 \mathrm{~g} / \mathrm{ml}$ at $40{ }^{\circ} \mathrm{C}$ [34]. Thus, the dynamic viscosity of the fat components can be estimated as $\sim 5 \times 10^{-2} \mathrm{~Pa}$ s. As the viscosity of the chocolate samples has serious nonNewtonian characteristics, it is not strictly valid to directly compare it with that of the pure fat components. If we ignore the non-Newtonian rheological characteristics of the chocolate samples, however, the chocolate samples appear to be roughly two orders of magnitude more viscous than the pure fat components (see table 3 ). It is only for the $\mathrm{ZrO}_{2} / \mathrm{ZrO}_{2}$ tribo-pair, however, that the chocolate samples provide lower friction forces than the pure fats. Clearly, this is related to particle embedment and abrasive wear in the PTFE-containing systems.

In general, if the hardness of an abrasive particle (sphere) is 1.25 times higher than that of the plane $\left(H_{a} / H_{s}>1.25\right.$ where $H_{a}$ and $H_{s}$ are the hardness of abrasive particle and plane respectively), it is expected that the particle indents the plane and vice versa [35]. Although the Vickers hardness of the organic particles in the chocolate samples is not well characterized, that of crystalline sucrose, which is the major component of the sugar, is known to be $755 \mathrm{Hv}$ [36]. This value is close to the lower limit of the hardness of silica particles [35]. Thus, the crystalline sucrose particles are sufficiently hard to deform PTFE and sufficiently soft to be deformed by $\mathrm{ZrO}_{2}$. Assuming that the actual Vickers hardness of the hardest particles in the chocolate samples is comparable to that of pure sucrose crystals, plastic indentation and abrasive wear by the particles in the chocolate sample is expected to occur exclusively toward PTFE. This accounts for the higher friction forces of the chocolate samples compared with the fat components for the tribo-pairs involving PTFE. 
The mechanism of the abrasive wear when particles are supplied via a continuous medium, e.g., a slurry, requires further consideration. Previous optical interferometry studies for a particle/oil system have shown that for the sliding contact in a sphere-on-plane configuration, lubrication by a slurry leads to an accumulation of particles at the inlet [15-17]. According to these studies, a portion of the accumulated particles was observed to be swept around the track, sometimes blocking the supply of oil into the contact area, while another fraction was observed to bypass the contact area. The particle accumulation at the inlet, however, does not completely exclude the possibility of a few particles passing through the contact area. The number of particles that can pass through the sliding contact, although significantly smaller than in the case of rolling contact [15-17], was observed to depend upon particle type, size, velocity and load. Theoretical studies have also led to a similar conclusion [27-29]. It should be emphasized that the hardness of the tribo-pair components would also play an important role in determining this behavior, although not much attention has been paid to this effect. Although optical interferometry allows the investigation of particle behavior in real space by providing images, the choice of disks for this method is limited to transparent materials and is thus not applicable to the materials in this study. Nevertheless, we believe that that the particle behavior in the surrounding region of the inlet, including accumulation, sweeping around, bypass, and entrainment, is generally applicable to all slurry-lubricated contacts.

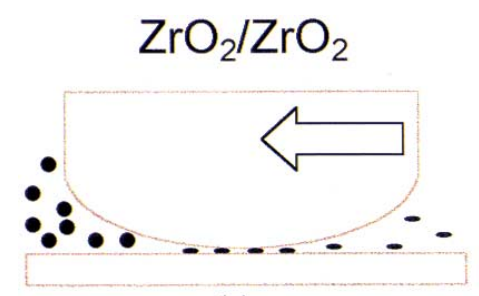

(a)
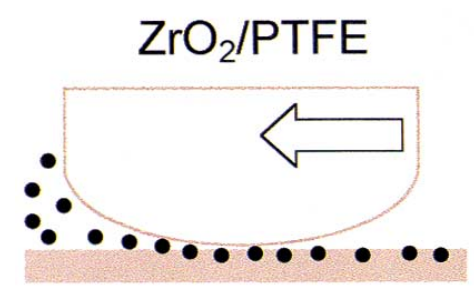

(c)

\subsection{Influence of the hardness of the tribo-pair on the lubrication properties of the chocolate samples}

As described in the previous section, the lubrication properties of the fluids containing particles are significantly influenced by the particle behavior at the perimeter of the contact area. This behavior is expected to be further influenced by the hardness of the tribopair, and we have systematically varied the configuration of the $\mathrm{ZrO}_{2}$ and PTFE tribo-pair in this work. For $\mathrm{ZrO}_{2} / \mathrm{ZrO}_{2}$, both surfaces are composed of harder material than the particles. Thus, this tribo-pair is considered to be free from abrasive wear by the particles in the chocolate samples. In fact, no evidence for the wear was observed on this tribo-pair when examined by optical microscopy. The lower friction forces observed for the chocolate samples compared with the fat components suggests that some particles are being entrained and passing through the contact area, consequently contributing to the formation of a better lubricant film than obtainable with the pure fat components. Several other possible modes of particle behavior, including accumulation at the inlet, sweeping around the sliding track, and starvation of the fat supply into the contact area, would cause higher or at least equivalent frictional forces. The entrainment of the particles into the contact area can cause abrasive wear and higher friction forces [27-29]. In the case of $\mathrm{ZrO}_{2} / \mathrm{ZrO}_{2}$, however, the influence of this effect seems negligible due to higher hardness of the surfaces. A schematic illustration for this mechanism is shown in figure $8(a)$.

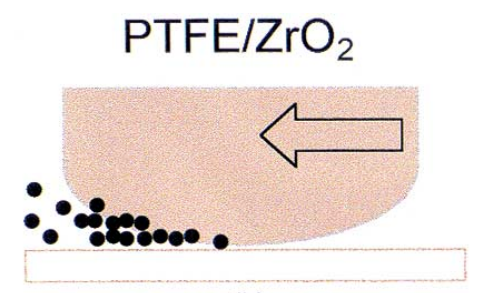

(b)

\section{PTFE/PTFE}

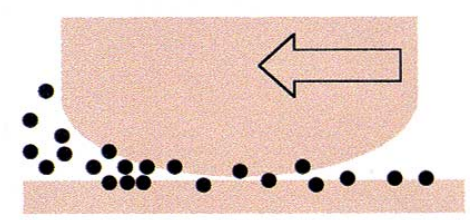

(d)

Figure 8. A schematic model of the particle behavior at the vicinity and contact area of the tribo-pairs (a) $\mathrm{ZrO}_{2} / \mathrm{ZrO}_{2}$; particles are deformed as they pass through contact area (b) PTFE $/ \mathrm{ZrO}_{2}$; particles accumulate at inlet and become embedded in pin (c) $\mathrm{ZrO} 2 / \mathrm{PTFE}$; particles become embedded in disk as they pass through contact area (d) PTFE/PTFE; particles become embedded in both pin and disk as they pass through contact area. The particles are dispersed in a continuous fat phase (not shown). 
For PTFE $/ \mathrm{ZrO}_{2}$, plastic indentation and abrasive wear is likely to occur only on the PTFE pin. This may increase the possibility of accumulating the particles at the sliding inlet as shown in figure 8(b). Thus, the accumulated particles are dragged around the $\mathrm{ZrO}_{2}$ disk and generate additional friction forces. This could account for the higher friction forces compared with $\mathrm{ZrO}_{2} / \mathrm{ZrO}_{2}$ case when the same chocolate sample is used as a lubricant. Due to the much higher hardness of the particles than the slider (PTFE), it is less likely that the particles can be entrained into and pass through the contact area than in the $\mathrm{ZrO}_{2} / \mathrm{ZrO}_{2}$ case.

For $\mathrm{ZrO}_{2} / \mathrm{PTFE}$, the same mechanism in PTFE $/ \mathrm{ZrO}_{2}$ case must be occurring. However, different particle behavior is also expected for a different contact configuration. As the soft part (PTFE) comprises the track and the hard part $\left(\mathrm{ZrO}_{2}\right)$ slides over it, the particles at the inlet are more likely to be embedded than sweep around the track. In other words, the sliding of the hard slider $\left(\mathrm{ZrO}_{2}\right)$ induces the embedding of the particles as well as passing over the embedded particles, as illustrated in figure 8(c). This behavior contrasts with the $\mathrm{ZrO}_{2} / \mathrm{ZrO}_{2}$ case, where the accumulated particles are deformed and contrasts with the PTFE $/ \mathrm{ZrO}_{2}$ case where the accumulated particles are dragged around the track.

For PTFE/PTFE, the particles are likely to be embedded in both pin and disk and the most serious abrasive wear would be expected. As the hardness of the slider and the track are equivalent, the accumulated particles at the inlet may be dragged around the track by the sliding as well as being embedded into the track, both of which contribute to friction forces (figure 8(d)). The generally higher friction forces obtained from PTFE/PTFE compared with the other tribo-pairs are consistent with this assumption.

\subsection{Influence of the textural/compositional features on the rheological and lubrication properties of the chocolate samples}

As is well known, the role of the surfactant (lecithin) in chocolate is to facilitate the homogeneous mixture of the hydrophilic particle components (e.g. sugar) with continuous fat phase and thus effectively reduce the viscosity [1]. However, if too much lecithin is added, normally more than $0.5 \mathrm{wt} \%$, the viscosity of chocolate increases, due to formation of micelles or bi-layers around the sugar by the excess lecithin [1]. This accounts for a distinctively reduced Casson yield value and Casson plastic viscosity of $\mathbf{C} \mathbf{1}$ and $\mathbf{F 4}$ compared with F1, while those of $\mathbf{C 4}$ are not further reduced. In other words, either increasing the particle size from 25 to $51 \mu \mathrm{m}$ on average or increasing the lecithin content from 0.1 to $0.4 \%$ results in a similar effect in reducing viscosity. The various rheological properties of the chocolate samples are thus believed to have resulted from the interplay of the particle size (and thus the surface area of the particles) and the lecithin content.

For the tribo-pairs involving $\mathrm{ZrO}_{2}\left(\mathrm{ZrO}_{2} / \mathrm{ZrO}_{2}\right.$, PTFE $/ \mathrm{ZrO}_{2}$, and $\mathrm{ZrO}_{2} / \mathrm{PTFE}$ ), the lubricating properties of the chocolate samples have been also observed in the order of F1 (highest friction), C1, F4 and C4 (lowest friction) and the distinction between different groups is clearer for lower velocities. For PTFE/PTFE, however, the $\mu$ values of $\mathbf{C 1}$ and $\mathbf{C} \mathbf{4}$ have been observed to be slightly higher than $\mathbf{F 1}$ and $\mathbf{F 4}$. In other words, the rheological properties of the chocolate samples are closely associated with their lubricating properties for the tribo-pairs involving $\mathrm{ZrO}_{2}$, while not for the tribopair composed of PTFE alone. For oil-based lubricants that are free from particles, the role of the rheological properties of a lubricant is normally discussed in terms of their performance to form a film at the contact area. For slurry lubricants, however, the lubricating properties need to be described in terms of particle behavior both in the contact area and also in the surrounding region.

As mentioned above, slurry-lubricated sliding allows some portions of the particles to accumulate at the entrainment edge, while some others are pushed away from the inlet and bypass the contact area. The subsequent behavior of the accumulated particles is strongly dependent upon the relative hardness of the tribo-pair/particles, as schematically illustrated in figure 8 . The number of accumulated particle is, however, thought to be closely associated with the rheological properties of the chocolate samples. In cases where the particle size is identical, yet rheological properties are clearly different, e.g., F1 versus $\mathbf{F 4}$, the particles in a less-viscous fluid (F4) possess higher mobility than those in more viscous fluid (F1). Consequently, they are more easily pushed away when subjected to shear interaction with the tribo-pair. This is most clearly manifested for the lubrication of $\mathrm{ZrO}_{2} / \mathrm{PTFE}$, in which the highly viscous lubricants (F1) generate the spiky friction signals, even outside the initial loading point (see figure 4(a)), while the least viscous lubricants limit such behavior to the loading point (C4) (figure 4(d)). As the embedding of the particles on the soft track, which is responsible for the spiky friction signals, is preceded by particle accumulation at the inlet, the absence of the spiky friction signals outside the loading point for $\mathbf{C 4}$ also suggests the absence of particle accumulation as well. Although the detailed particle behavior after accumulation may be different for the other tribo-pairs, the same mechanism is believed to be mainly responsible for the higher friction forces for the more viscous chocolate samples. This must be applicable to even for PTFE/PTFE. However, the abrasive wear mechanism dominates the rheological properties of the fluid due to softness of both surfaces. 


\section{Conclusions}

We have revealed the rheological and lubrication properties of a series of model chocolate samples with systematically different textural/compositional features. Four permutations of a hard $\left(\mathrm{ZrO}_{2}\right)$ and a soft (PTFE) material have been realized for the tribo-pairs; $\mathrm{ZrO}_{2} / \mathrm{ZrO}_{2}$, PTFE$/ \mathrm{ZrO}_{2}, \mathrm{ZrO}_{2} / \mathrm{PTFE}$, and PTFE/ PTFE. Particle size and surfactant (lecithin) content were observed to significantly influence the rheological properties; either increasing the lecithin content (from 0.1 to $0.4 \mathrm{wt} \%$ ) or increasing the mean particle size (from 21 to $52 \mu \mathrm{m}$ ) reduced both the Casson yield value, $\tau_{\mathrm{ca}}$, and the Casson plastic viscosity, $\eta_{\mathrm{ca}}$. The lubrication properties of the chocolate samples were also observed to be dependent upon the textural/compositional characteristics of the chocolate samples, and further influenced by the choice of the tribo-pairs. For $\mathrm{ZrO}_{2} / \mathrm{ZrO}_{2}$, the chocolate samples showed lower friction forces, while the other tribo-pairs involving PTFE (PTFE/ $\mathrm{ZrO}_{2}, \mathrm{ZrO}_{2} / \mathrm{PTFE}$, and PTFE/PTFE) showed higher friction forces compared with the particle-free fat components. The difference is understood in terms of the relative hardness of the particles and the tribo-pair, influencing particle behavior at the srrounding region of the sliding contact. It seems that these results indicate that the relative hardness of the particles with respect to tribo-pair should be considered in the case of slurrylubricated contacts, in order to fully account for tribological phenomena.

\section{References}

[1] S.T. Beckett, The Science of Chocolate (Royal Society of Chemistry Paperbacks, 2000).

[2] J. Chevally, Industrial Chocolate Manufactures and Uses, 3rd ed. (Blackwell Science Ltd., Oxford).

[3] N. Casson, Br. Soc. Rheol. Bull 52(5)(1957).

[4] N. Casson, Rheology of Disperse Systems (Pergamon Press, New York, 1959).
[5] G. Luengo, M. Tsuchiya, M. Heuberger and J.N. Israelachvili, J. Food. Sci. 62 (1997) 767.

[6] S. Lee, M. Heuberger, P. Rousset and N.D. Spencer, J. Food Sci. 67 (2002) 2712.

[7] H.F. Barry and J.P. Binkelman, Lub. Eng. April (1966) 139.

[8] R.C. Rosenberg and W.E. Campbell, Lub. Eng. February (1968) 92.

[9] W.J. Bartz, Wear 17 (1971) 421.

[10] W.J. Bartz and K. Müller, Wear 20 (1972) 371.

[11] J. Gänsheimer and R. Holinski, Wear 19 (1972) 439.

[12] R. Holinski, ASLE Trans. 18(4) (1974) 263.

[13] Y. Tsuya, K. Saito and H. Suzuki, Lub. Eng., 31(12) (1975) 619.

[14] B.K. Gupta and B. Bhushan, Lub. Eng. 50(7) (1994) 524.

[15] G.T.Y. Wan and H.A. Spikes, STLE Trans. 31(1) (1987) 12.

[16] C. Cusano and H.E. Sliney, ASLE Trans. 25(2) (1982) 190.

[17] C. Cusano and H.E. Sliney, ASLE Trans. 25(2) (1982) 183.

[18] Z. Wu and D.W. Dareing, Tribol. Trans. 37(4) (1994) 836.

[19] A. Batra and D.W. Dareing, Tribol. Trans. 38(1) (1995) 161

[20] M. Shen, J. Luo and S. Wen, Tribol. Trans. 44 (2001) 494.

[21] K. Mizuhara, M. Tomimoto and T. Yamamoto, Tribol. Trans. 43(1) (2000) 51.

[22] P.L. Wong, W.A. Bullough, C. Feng and S. Lingard, Wear 247 (2001) 33.

[23] A.E. Yousif and M. Nacy, Wear 172 (1994) 23.

[24] M.M. Khonsari and V. Esfahanian, J. Tribol. 110 (1988) 367.

[25] D.Y. Hua and M.M. Khonsari, J. Tribol. 118 (1996) 67.

[26] M.M. Khonsari, Wear 207 (1997) 55.

[27] G.K. Nikas, R.S. Sayles and E. Ioannides, Proc. Inst. Mech. Eng. 212J (1998) 333.

[28] G.K. Nikas, J. Tribol. 123 (2001) 83.

[29] G.K. Nikas, J. Tribol. 124 (2002) 461.

[30] A.W. Ruff, Tribology Data Handbook E.R. Booser, ed. (CRC Press, New York, 1997).

[31] E. Hornbogen and K. Schäfer, Fundamentals of Friction and Wear of Materials D.A. Rigney, ed. (American Society for Metals, Ohio, 1981).

[32] D.C. Evans and J.K. Lancaster, Treatise on Materials Science and Technology Vol. 13 Wear, D. Scott, ed. (Academic Press Inc., London, 1979).

[33] D.F. Moore, Principles and Applications of Tribology, Ch. 5 (Pergamon Press, Oxford, 1975).

[34] D. Swern, Bailey's Industrial Oil and Fat Products D. Swern, ed. 3rd ed. Ch. 3, (John Wiley \& Sons, 1964).

[35] I.M. Hutchings, Tribology, Friction and Lubrication of Engineering Materials (Edward Arnold, 1992).

[36] Z. Bubnik, P. Kadlec, D. Urban and M. Bruhns, Sugar Technologists Manual, 8th edn. (Bartens, Berlin, 1995). 